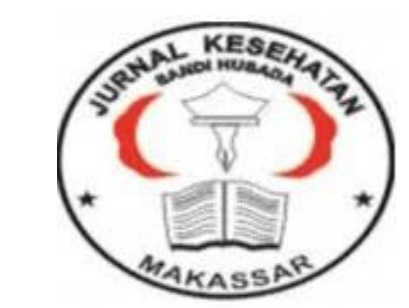

\author{
Jurnal Ilmiah Kesehatan Sandi Husada
}

hhttps://akper-sandikarsa.e-journal.id/IIKSH

Vol 9, No, 1, Juni 2020, pp;456-460

p-ISSN: 2354-6093 dan e-ISSN: 2654-4563

DOI: $10.35816 /$ jiskh.v10i2.321

\title{
Faktor Yang Mempengaruhi Kedisiplinan Perawat
}

\section{ARTIKEL PENELITIAN}

The Factors that Influence the Discipline of Nurses

\author{
Arnianti Arnianti 1 \\ ${ }^{1}$ Keperawatan, Sekolah Tinggi Ilmu Kesehatan YAPIKA Makassar
}

\begin{abstract}
Artikel info
Artikel history:

Received; 20 April 2020

Revised: 27 Mei 2020

Accepted; 28 Mei 2020
\end{abstract}

\begin{abstract}
.
Discipline is a matter that becomes a benchmark to find out whether the role of a manager or leader as a whole can be implemented properly or not. Discipline is also a form of nurses 'self-control and regular implementation in demonstrating the level of sincerity of nurses' work in a Health center, where nurses who do not comply with the regulations set by the Health centerl will get sanctions. Therefore this disciplinary action cannot be applied carelessly, so it requires wise consideration. This study aims to determine the discipline of nurses in Maros Barui Health center. This research is quantitative research. The sample in this study amounted to 50 respondents. Samples were taken with cross sectional design, using non rundem sampling method with criteria determined by researchers. The results of the chi-squer test for personality and environmental factors obtained a $p$ value of 0.827 that Ha was rejected and HO was accepted. The application of the results of this study can be used as a reference material for learning about nurse discipline. his duty.
\end{abstract}

Abstrak.

Kedisiplinan merupakan suatu hal yang menjadi tolak ukur untuk mengetahui apakah peran seorang manajer atau pimpinan secara keseluruhan dapat dilaksanakan dengan baik atau tidak. Disiplin juga merupakan bentuk dari pengendalian diri perawat dan pelaksanaan yang teratur dalam menunjukkan tingkat kesungguhan kerja perawat pada suatu Puskesmas, dimana para Perawat yang tidak mematuhi peraturan yang telah di tetapkan Puskesmas akan mendapatkan sanksi. Oleh karena itu tindakan disiplin ini tidak bisa diterapkan secara sembarangan, sehingga memerlukan pertimbangan yang bijak. Penelitian ini bertujuan untuk mengetahui kedisiplinan perawat di PKM Maros Baru Kab.Maros. Penelitian ini merupakan penelitian kuantitatif. Sampel dalam penelitian ini berjumlah 50 responden. dengan desain penelitian potong lintang atau 
cros sectional, dengan menggunakan metode non rundem sampling dengan kriteria yang ditetapkan peneliti. Hasil chisquer test faktor kepribadian dan lingkungan didapatkan nilai $p$ value sebesar 0,827 bahwa Ha di tolak dan $\mathrm{HO}$ di terima.Diharapkan Hasil penelitian ini dapat dijadikan bahan acuan untuk belajar tentang kedisiplinan perawat dan Diharapkan bagi petugas kesehatan agar penelitian ini dijadikan bahan masukan untuk menjalankan tugasnya.

\begin{tabular}{lr}
\hline Keywords: & $\begin{array}{c}\text { Corsponden author: } \\
\text { Discipline; }\end{array}$ \\
Personality; & Email: $\begin{array}{l}\text { arnianti1987@gmail.com } \\
\text { Environment; }\end{array}$ \\
& artikel dengan akses terbuka dibawah lisensi BCC BY NC ND-4.0
\end{tabular}

\section{Pendahuluan}

Menurut (Baynham, etal, 2002) World healt organization (WHO), bahwa dalam rangka peningkatan kinerja perawat baik dalam penegakan disiplin terhadap perawat harus dapat memberikan kenyaman maupun kepuasan terhadap perawat sebagai apresiasi atas kinerja yang mereka lakukan. Berdasarkan data rekam medik yang diperoleh di PKM Maros Baru Kab.Maros, bahwa jumlah perawat secara keseluruhan adalah 124 orang. (Rekammedik, 2019).

Perawat sebagai salah satu aset yang penting dalam penyelenggaraan sarana kesehatan di rumah sakit maupun puskesmas memiliki peran yang sangat penting, selain sebagai tenaga paramedik untuk merawat pasien, oleh karena tugas-tugas yang sangat penting tersebut maka perawat seharusnya memiliki kedisiplinan kerja yang tinggi, sebagai contoh tentang kedisiplinan kerja dikaitkan dengan risiko yang mungkin terjadi, bagi perawat yang tidak disiplin keterlambatan menangani pasien (bahkan dalam hitungan detik pun) akan sangat membahayakan keselamatan nyawa pasien (Yatnikasari, 2010).

Kedisiplinan merupakan suatu hal yang menjadi tolak ukur untuk mengetahui apakah peran seorang manajer atau pimpinan secara keseluruhan dapat dilaksanakan dengan baik atau tidak. Keperawatan adalah salah satu profesi di rumah sakit maupun dipuskesmas yang berperan penting dalam penyelenggaraan upaya menjaga mutu pelayanan kesehatan di puskesmas maupun Rumah Sakit. Pelayanan kesehatan di puskesmas merupakan bentuk pelayanan yang diberikan kepada klien, oleh suatu tim multi disiplin termasuk tim keperawatan. Tim keperawatan merupakan anggota tim kesehatan yang menghadapi masalah kesehatan klien selama 24 jam secara terus menerus (Yeni, 2017).

Puskesmas memiliki peran dalam upaya meningkatkan kesehatan masyarakat yang setinggi-tingginya. Dalam upaya pencapaian derajat kesehatan masyarakat tersebut, puskesmas maupun rumah sakit menyelenggarakan upaya pelayanan kesehatan yang terjangkau dan bermutu bagi masyarakat (Rifai, etal, 2016). Untuk meningkatkan pelayananya, salah satu faktor penting yang harus diperhatikan oleh Rumah Sakit maupun puskesmas adalah Sumber Daya Manusia (SDM). Menjelaskan bahwa keberhasilan suatu institusi ditentukan oleh dua faktor utama,yaitu Sumber Daya Manusia atau Tenaga kerja dan sarana prasarana pendukung atau fasilitas kerja (Dessler, 2015). adalah orang yang bekerja atau menjadi anggota suatu organisasi yang disebut personil, pegawai, karyawan, pekerja, tenaga kerja,dan lain-lain (Nawawi, 2005). 


\section{Metode}

Penelitian ini menggunakan metode penelitian kuantitatif yang didukung oleh data kualitatif dengan desain penelitian potong lintang atau cros sectional, dimana variable independen (variabel yang mempengaruhi) dan variabel dependen (variabel yang dipengaruhi) diukur dan diamati pada waktu yang sama.

\section{Hasil Dan Pembahasan}

Tabel 1. Analisis Faktor Kepribadian terhadap kedisiplinan Perawat Di PKM Maros Baru Kabupaten Maros

\begin{tabular}{|c|c|c|c|c|}
\hline Faktor & \multicolumn{2}{|c|}{ Kedisiplinan } & total & Nilai $p$ \\
\hline Kepribadian & Baik & Kurang baik & & \\
\hline Baik & 47 & 0 & 47 & \\
\hline Kurang baik & 0 & 3 & 3 & 0,827 \\
\hline Total & 7 & 3 & 50 & \\
\hline
\end{tabular}

Sumber : Data primer yang diolah, 2019

Tabel 2. Analisis Faktor Lingkungan terhadap kedisiplinan Perawat Di PKM Maros Baru Kabupaten Maros

\begin{tabular}{|c|c|c|c|c|}
\hline Faktor & \multicolumn{2}{|c|}{ Kedisiplinan } & total & Nilai p \\
\hline Lingkungan & Baik & Kurang baik & & \\
\hline Baik & 47 & 0 & 47 & 0,827 \\
\hline Kurang baik & 0 & 3 & 3 & \\
\hline Total & 447 & 3 & 50 & \\
\hline
\end{tabular}

Sumber : Data primer yang diolah, 2019

Hasil analisis faktor kepribadian terhadap kedisiplinan perawat di PKM Maros Baru Kabaputen Maros setelah diberikan kuesioner menunjukkan nilai signifikan 0,827 >0,05 yang artinya Ha di tolak dan HO diterima. Hal ini menunjukan bahwa faktor kepribadian terhadap kedisiplinan tidak ada pengaruh. Faktor yang penting dalam diri kepribadian seseorang adalah sistem nilai yang dianut, sistem nilai dalam hal ini yang berkaitan langsung dengan disiplin. Nilai-nilai yang menjunjung disiplin yang diajarkan atau ditanamkan orang tua, guru, dan masyarakatakan digunakan sebagai kerangka acuan bagi penerapan disiplin di tempat kerja. Sistem nilai akan terlihat dari sikap seseorang dan sikap diharapkan akan tercermin dalam perilaku.

Penelitian ini sejalan dengan penelitian yang dilakukan (Meidian, 2012) menunjukkan bahwa tidak terdapat hubungan yang bermakna antara motivasi terhadap kondisi kerja dengan disiplin kerja. Hasil tersebut sejalan dengan yang disampaikan M.Soemargono (1996) bahwa tidak ada hubungan yang bermakna antara kondisi lingkungan kerja dengan kinerja perawat. Penelitian lain yang sejalan yaitu (Prasojo, 2005) yang menyimpulkan bahwa tidak ada hubungan yang signifikan antara kesempatan berkembang dengan disiplin kerja. Dengan begitu dapat disimpulkan bahwa faktor lingkungan tidak ada pengaruh terhadap kedisiplinan perawat di PKM Maros Baru Kabupaten Maros. 
Upaya menanamkan kedisiplinan pada dasarnya adalah menanamkan nilai-nilai guna mencapai tujuan Puskesmas Berdasarkan pernyataan-pernyataan di atas, dapat ditarik kesimpulan bahwa faktor-faktor yang mempengaruhi Kedisiplinan perawat adalah faktorfaktor dari luar individu yaitu kepemimpinan, peranan yang berlaku di lingkungan kerja serta faktor dari dalam yaitu moral atau semangat dan kesadaran dari Perawat akan pentingnya disiplin kerja, disiplin karena kepatuhan akan komitmen yang ada, dan kepatuhan yang didasarkan pada identifikasi. Hasil analisis faktor lingkungan terhadap kedisiplinan perawat di PKM Maros Baru Kabupaten Maros setelah di berikan kuesioner menunjukkan nilai signifika n 0,827 > 0,05 yang artinya Ha ditolak dan H0 diterima, Hal ini menunjukan bahwa faktor lingkungan terhadap kedisiplinan tidak ada pengaruh.

Penelitian ini sejalan dengan penelitian yang dilakukan oleh (Dwi Septianto,etal, 2011) yang menganalisis pengaruh lingkungan kerja dan stress kerja terhadap kinerja karyawan dengan kesimpulan pengaruh positif lingkungan kerja dengan kinerja ditolak karena diperoleh nilai signifikan sebesar 0,102. Hasil analisis sengan menggunakan chis square diperoleh nilai $\mathrm{p}$ value $=0,332$ atau nilai $\mathrm{p}>0,05$. Dengan demikian maka $\mathrm{H} 0$ diterima dan Ha ditolak sehingga dapat disimpulkan bahwa tidak ada hubungan yang bermakna antara lingkingan kerja dengan kinerja perawat rawat inap di RSUD Tugurejo Semarang.

Penelitian ini sejalan dengan hasilpenelitian (Suprapto, 2016) menunjukkan bahwa tidak ada hubungan antara pendidikan, kondisi lingkungan kerja dengan mutu pelayanan keperawatan di Ruangan Instalasi Rawat Darurat Rumah Sakit Daerah Salewangan Maros dengan $\mathrm{p}>0,05$, dan ada hubungan antara beban kerja dengan mutu pelayanan keperawatan di Ruangan Instalasi Rawat Darurat Rumah Sakit Daerah Salewangan Maros dengan $p=0,003$. Ada hubungan antara faktor hubungan interpersonal dengan mutu pelayanan keperawatan di Ruangan Instalasi Rawat Darurat Rumah Sakit Daerah Salewangan Maros dengan $\mathrm{p}=0,004$. Berdasarkan hasil penelitian ini disimpulkan bahwa faktor-faktor stres kerja perawat dengan mutu pelayanan keperawatan di Ruangan Instalasi Rawat Darurat Rumah Sakit Daerah Salewangan Maros adalah faktor beban kerja dan hubungan interpersonal.

Bertentangan dengan hasil penelitian (Rumoning, 2018) menunjukkan bahwa lingkungan kerja berpengaruh positif tapi tidak signifikan terhadap komitmen organisasi. Disiplin kerja dan stress kerja berpengaruh positif dan signifikan terhadap komitmen organisasi Lingkungan kerja berpengaruh positif dan signifikan secara langsung tehadap kinerja perawat tanpa harus melalui komitmen organisasi. Disiplin kerja secara langsung berpengaruh tetapi tidak signifikan terhadap kinerja perawat, akan tetapi secara tidak langsung disiplin kerja berpengaruh positif dan signifikan terhadap kinerja perawat melalui komitmen organisasi. Dengan begitu dapat disimpulkan bahwa faktor kepribadian dan lingkungan tidak ada pengaruh terhadap kedisiplinan perawat di Puskesmas Maros Baru KabupatenMaros. 


\section{Simpulan Dan Saran}

Berdasarkan penelitian yang telah di lakukan maka dapat di simpulkan bahwa; tidak ada pengaruh antara faktor kepribadian dan lingkungan terhadap kedisiplinan perawat di PKM Maros Baru Kabupaten Maros. Hasil penelitian ini dapat dijadikan bahan acuan untuk belajar tentang kedisiplinan perawat bagi petugas kesehatan agar penelitian ini bahan masukan untuk menjalankan tugasnya dengan baik.

\section{Daftar Rujukan}

Baynham, M., Lea, M., \& Stierer, B. (2002). Academic writing in new and emergent discipline areas. Supporting Lifelong Learning: Perspectives on Learning, 1, 188.

Dessler, A. (2015). Introduction to modern climate change. Cambridge University Press.

Dwi Septianto, D. S., \& Lataruva, E. (2011). Pengaruh lingkungan kerja dan stres kerja terhadap kinerja karyawan studi pada PT Pataya Raya Semarang. Universitas Diponegoro.

Meidian, F. A. (2012). Analisis Hubungan Faktor-Faktor Motivasi Kerja terhadap Disiplin Kerja Pegawai Non Medis di Gedung Administrasi RS X. Skripsi Fakultas Kesehatan Masyarakat Universitas Indonesia. Hal, 1-21.

Nawawi. (2005). Managemen Strategik: Organisasi Non Profit Bidang Pemerintahan. Yogyakarta: UGM.

Prasojo, S. (2005). Hubungan karakteristik dan motivasi dengan disiplin kerja perawat pelaksana di ruang rawat inap RSUD Batang. 27182.

Rekammedik. (2019). Rekam Medik Puskesmas Maros Baru Kabupaten Maros. Maros: Puskesmas Baru.

Rifai, M., Madjid, U., \& Ismunarta, I. (2016). Implementasi Kebijakan tentang Standar Pelayanan Minimal Bidang Kesehatan di Puskesmas Garawangi Kabupaten Kuningan Provinsi Jawa Barat. Jurnal Politik Pemerintahan, 9(1), 25-43.

Rumoning, M. H. (2018). Pengaruh Lingkungan Kerja, Disiplin Kerja dan Stres Kerja terhadap Komitmen Organisasi dalam Meningkatkan Kinerja Perawat Di RSUD Kabupaten Asmat. Jurnal EMBA: Jurnal Riset Ekonomi, Manajemen, Bisnis Dan Akuntansi, 6(2).

Suprapto, S. (2016). Faktor Stres Kerja Perawat Yang Berhubungan Dengan Mutu Pelayanan Keperawatan Di Instalasi Rawat Darurat Rs Daerah Salewangan Kabupaten Maros. Jurnal Ilmiah Kesehatan Sandi Husada, 4(1), 1-10.

Yatnikasari, A. (2010). Hubungan Antara Program Retensi dengan Komitmen Organisasi Perawat Pelaksana di RSAB Harapan Kita Jakarta. Tesis.

Yulian, R., \& Yeni, Y. (2017). Optimalisasi Pelayanan (Service) Puskesmas Dalam Peningkatan Kualitas Pelayanan Kesehatan Masyarakat Di Kabupaten Kubu Raya Provinsi Kalimantan Barat. Jurnal Manajemen Motivasi, 13(2), 850-867. 